\title{
A Simple Screening Method for Extra Virgin Olive Oil Adulteration by Determining Squalene and Tyrosol
}

\author{
Tatsuya Hayakawa', Miran Yanagawa', Atsushi Yamamoto², Sen-ichi Aizawa ${ }^{3}$, \\ Atsushi Taga ${ }^{4}$, Naoki Mochizuki ${ }^{5}$, Yutaka Itabashi ${ }^{6}$, Hajime Uchida ${ }^{7}$, Yoshimi Ishihara ${ }^{1}$, \\ and Shuji Kodama ${ }^{1 *}$

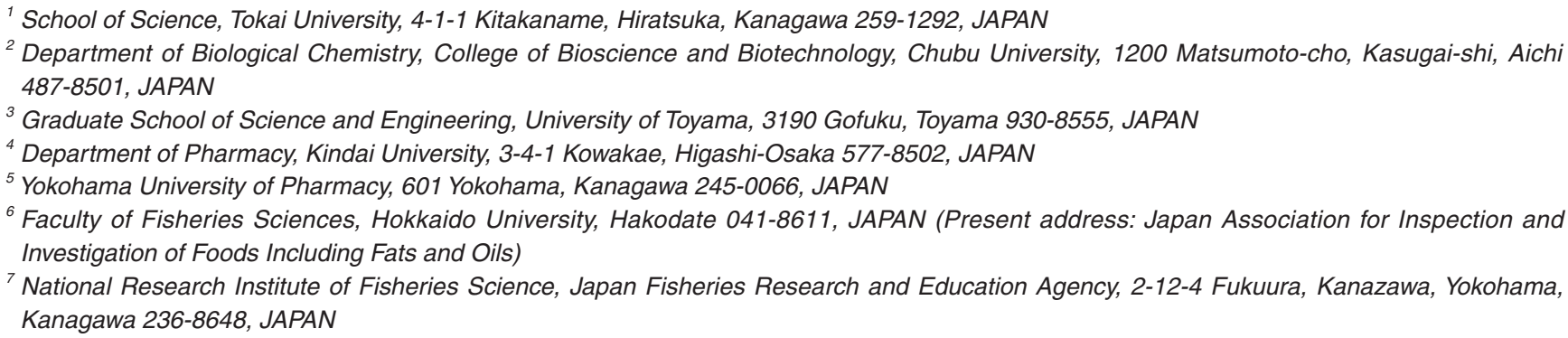

\begin{abstract}
A simple screening method for discrimination between commercial extra virgin olive oils and their blends with other vegetable oils was developed. Squalene, which was contained relatively high amounts in virgin olive oil, was determined by HPLC after a simple pretreatment that was carried out by dilution of oil samples with 2-propanol. Tyrosol, which was contained at relatively high concentration in virgin olive oil among phenolic compounds, was determined by HPLC after a simple liquid-liquid extraction. When using squalene and tyrosol contents as axes, extra virgin olive oils could be discriminated from pure olive oils, blended oils (extra virgin olive oils with sunflower oil or grapeseed oil) and other vegetable oils. These results suggest that determining squalene and tyrosol in seed oil samples could be useful in distinguishing between extra virgin olive oil and blended oils as a screening method.
\end{abstract}

Key words: extra virgin olive oil, adulteration, squalene, tyrosol, HPLC

\section{Introduction}

Virgin olive oil is obtained from the fruit of the olive trees using only mechanical extraction. Among virgin olive oils, extra virgin olive oil is defined as the oil with excellent flavor and odor and a free fatty acid, expressed as oleic acid, of not more than $0.8 \mathrm{~g} / 100 \mathrm{~g}^{1-3)}$. Refined olive oil is the oil from virgin olive oil by means of refining methods that do not lead to alteration in the initial glyceride structure. Olive oil or pure olive oil is classified as a mixture of refined olive oil and virgin olive oil. The price of extra virgin olive oil is usually more expensive than that of other vegetable oils such as sunflower, corn, rapeseed oils and so on. Thus, extra virgin olive oil is sometimes adulterated or mislabeled with other less expensive vegetable oils ${ }^{4,5)}$. In order to detect extra virgin olive oil adulteration, it is necessary to clarify the difference of components between extra virgin olive oil and other vegetable oils. Extra virgin olive oil is mainly composed of two components, saponifiables and unsaponifiables ${ }^{5-7)}$. The former consists of triacylglycerols, partial acylglycerols, free fatty acids, and phospholipids, which represent more than $98 \%$ of the oil weight, while the later includes more than 230 chemical components, consisting of phenolics, phytosterols, carotenoids, chlorophyll and squalene. Commercial vegetable oils are traditionally produced by sorbent extraction and refining processes ${ }^{5,8)}$, in which the great majority of minor components as well as unwanted side products are removed.

There are around 2,500 varieties of olives, of which 250 varieties are classified as commercial cultivars by the International Olive Oil Council ${ }^{5}$. It is well known that chemical composition of extra virgin olive oil can be affected by variety of olive tree and/or geographic origin ${ }^{9)}$. Practically, it is not clear whether a commercial extra virgin olive oil

\footnotetext{
*Correspondence to: Shuji Kodama, School of Science, Tokai University, 4-1-1 Kitakaname, Hiratsuka, Kanagawa 259-1292, JAPAN E-mail: kodama@tokai-u.jp Accepted March 16, 2020 (received for review February 6, 2020) Journal of Oleo Science ISSN 1345-8957 print / ISSN 1347-3352 online http://www.jstage.jst.go.jp/browse/jos/ http://mc.manusriptcentral.com/jjocs
} 
with such a description on the label is genuine or adulterant, what kinds of extra virgin olive oil and vegetable oil were used, and how ratios of extra virgin olive oil and adulterated vegetable oil were mixed. Thus it is significantly difficult to identify extra virgin olive oils adulterated with small amount of vegetable oil in commercial extra virgin olive oil products, in the case that the identity of a potential adulteration is unknown.

Near-infrared ${ }^{4,10)}$, mid-infrared ${ }^{11)}$, Fourier-transform infrared ${ }^{12)}$, and Raman ${ }^{13)}$ spectroscopies combined with chemometric methods have been used to detect extra virgin olive oil adulteration. Chromatographic techniques combined with chemometric methods for analysis of free fatty acids and triacylglycerols have been also developed to determine extra virgin olive oil adulteration ${ }^{14-17)}$. Minor components, including phenolics ${ }^{18,19)}$, squalene $e^{19,20)}$, waxes ${ }^{6)}$, and so on, have been used for evaluation of quality and characterization of virgin olive oil. However, these chromatographic methods needed tedious time-consuming pretreatments and long analysis times.

In this study, we selected two minor components, squalene and tyrosol to determine adulteration of extra virgin olive oil, in which a large amount of adulterant vegetable oil was contained. Squalene is a triterpene hydrocarbon and a key intermediate in cholesterol biosynthesis. It was reported that virgin olive oils contained relatively high amount of squalene, ranging between $1.10 \mathrm{mg} / \mathrm{g}$ and 8.39 $\mathrm{mg} / \mathrm{g}$, compared to other vegetable oils ${ }^{20)}$. This variety for squalene concentration may result from cultivar, fruit ripeness, and agroclimatic conditions. Owen et al. ${ }^{19)}$ analyzed phenolic compounds and squalene in extra virgin olive oils and refined olive oils, and concluded that these compounds in extra virgin olive oils were significantly higher than those in refined olive oils. Tyrosol and hydroxytyrosol, which are simple phenols, were reported to be contained at higher concentration than other phenolics in virgin olive $\mathrm{oil}^{7}{ }^{7}$. These phenols increased their concentration in virgin olive oils with maturation of fruits ${ }^{21)}$. And also, refining processes could cause significant loss of phenolics as well as squalene ${ }^{5,21)}$. Squalene, tyrosol, and hydroxytyrosol are commercially available, but hydroxytyrosol is much more expensive than the other two compounds.

This paper reports a simple screening method to distinguish extra virgin olive oils from pure olive oils and blended oils (extra virgin olive oils with sunflower oil or grapeseed oil) by determining squalene and/or tyrosol using versatile HPLC methods. Squalene and tyrosol in extra virgin olive oil were the major components in hydrocarbons and phenolic compounds, respectively. The advantages of the proposed method for the analysis of only two components are not to need any tedious and time-consuming sample pretreatments, long analysis times and chemometric methods.

\section{Experimental Procedures}

\subsection{Materials}

Acetonitrile and 2-propanol were obtained from Sigma (St. Louis, MO, USA). Squalene, tyrosol, and the other chemicals (analytical grade) used were from Tokyo Kasei (Tokyo, Japan).

\subsection{Apparatus for HPLC and mobile phase conditions}

The HPLC system consisted of a Hitachi(Tokyo, Japan) Model L-6300 pump, a Shimadzu(Kyoto, Japan) Model SPD-10AD detector, a Rheodyne (Cotati, CA, USA) manual injector, a Shimadzu (Kyoto, Japan) Model CTO-10Avp column oven, and a Flom(Tokyo, Japan) Model Gastorr degasser. For analysis of squalene, Sunshell C18 column(2.6 $\mu \mathrm{m}, 4.6 \mathrm{~mm}$ i.d. $\times 100 \mathrm{~mm}$, ChromaNik Technologies, Osaka, Japan) was used. The mobile phase consisted of acetonitrile (A) and 2-propanol (B) (0-35 min with 10-50\% $\mathrm{B}$ by gradient elution; $35-60$ min with $50 \% \mathrm{~B}$ ). Elution was carried out at a flow rate of $0.8 \mathrm{~mL} / \mathrm{min}$ at $35^{\circ} \mathrm{C}$ and squalene was detected at $215 \mathrm{~nm}$. For analysis of tyrosol, InertSustain AQ-C18 column $(5 \mu \mathrm{m}, 4.6 \mathrm{~mm}$ i.d $\times 100 \mathrm{~mm}$, GC Scineces, Tokyo, Japan)was used with the mobile phase consisted of $0.1 \%$ phosphoric acid and $15 \%$ acetonitrile. Elution was carried out at a flow rate of $1.5 \mathrm{~mL} / \mathrm{min}$ at $35^{\circ} \mathrm{C}$ and tyrosol was detected at $280 \mathrm{~nm}$. Data acquisition and processing were conducted with a Chromato-PRO (Runtime Instrument, Kanagawa, Japan).

\subsection{Sample extraction and preparation}

Ten brands of extra virgin olive oils, one brand of virgin olive oil, two brands of pure olive oils, five brands of sunflower oils, two brands of rapeseed oils, grapeseed oils, and avocado oils, one brand of safflower oil, linseed oil, corn oil, soybean oil, rice bran oil, and peanut oil were purchased from local markets. Extra virgin olive oils were obtained from J-Oil Mills Inc. (Tokyo, Japan), Nisshin OilliO Group, Ltd. (Tokyo, Japan), Kikkoman Corpolation(Tokyo, Japan), Ajinomoto Co. Inc. (Tokyo, Japan), and S. Ishimitsu \& Co. Ltd. (Kobe, Japan). Five brands of blended oils (C1-C5, extra virgin olive oil / sunflower oil, 20/80), and a brand of blended oil (C6, extra virgin olive oil / grapeseed oil, 30/70) were the products of Zucchi, Torre del Sole, Colavita, and so on. For determination of squalene, each oil sample was diluted 20-fold with 2-propanol and was analyzed by HPLC as described above. Recovery examination was conducted by adding squalene $(0.1 \mathrm{mg} / \mathrm{mL})$ in each diluted oil solution. For determination of tyrosol, $4 \mathrm{~mL}$ of each oil and $4 \mathrm{~mL}$ of acetonitrile was mixed. After shaking vigorously, the mixture was centrifuged at approximately $1200 \times g$ for 5 min and upper layer (acetonitrile layer) was injected into the HPLC column. Recovery examination was conducted by adding $4 \mathrm{~mL}$ of $0.1 \mathrm{mM}$ tyrosol-acetonitrile solution instead of acetonitrile to $4 \mathrm{~mL}$ of each oil sample. 


\section{Results and Discussion}

\subsection{Analysis of squalene}

Squalene has been analyzed by HPLC methods with various pretreatments so far. Grigoriadou et $a l^{22)}$ analyzed squalene in virgin olive oil by HPLC after fractional crystallization, saponification, or silica cartridge purification as pretreatment of oil samples. In GC analysis, solid-phase microextraction $^{23)}$ and saponification ${ }^{20)}$ were used as pretreatment of oil samples to remove triacylglycerols. Owen et $a l .{ }^{19)}$ analyzed squalene in virgin olive oil and refined olive oil. Oil samples were diluted with diethyl ether, and the diluted samples were directly analyzed by GC/MS. However, the GC column was replaced after every 10 injections due to deterioration of the column performance caused by triacylglycerols.

In our preliminary study, we tried to separate triacylglycerols in extra virgin olive oil and sunflower oil using HPLC with ODS columns and gradient elution with acetonitrile/2propanol, acetonitrile/tert-butyl methyl ether, methanol/2propanol, and methanol/tert-butyl methyl ether. Triacylglycerols in these samples could not be fully separated by HPLC using these gradient elution media, but separation of triacylglycerols using gradient elution media consisting of acetonitrile and 2-propanol was better than that using the other three media and separation of peak of squalene and unknown minor peaks was also the best among the above media. Thus, HPLC method for analysis of squalene was conducted by using the gradient elution media consisting of acetonitrile and 2-propanol as described in Experimental section.

Squalene was subjected to the proposed HPLC method using the above optimum conditions. The limit of detection (LOD) of squalene defined as a signal-to-noise ratio of 3 was $0.042 \mathrm{mg} / \mathrm{L}$ and the limit of quantification(LOQ) of squalene as a signal-to-noise ratio of 10 was $0.126 \mathrm{mg} / \mathrm{L}$. Linearity $\left(r^{2}>0.999\right)$ was demonstrated in the concentration range of $0.126-300 \mathrm{mg} / \mathrm{L}$ by standard curve ( 7 points) for squalene. The repeatability of five consecutive determinations of squalene was evaluated at $30 \mathrm{mg} / \mathrm{L}, 100 \mathrm{mg} / \mathrm{L}$, and $300 \mathrm{mg} / \mathrm{L}$. Good repeatabilities of peak areas $(\mathrm{RSD}<$ $2.0 \%)$ and retention times $(\mathrm{RSD}<0.5 \%)$ were obtained. Interday repeatabilities of peak areas and retention time of squalene in three days $(n=5$, each day)were $1.6 \%$ and $0.8 \% \mathrm{RSD}$, respectively, at $100 \mathrm{mg} / \mathrm{L}$. When a standard solution was added to diluted sample solutions (extra virgin olive oil, sunflower, avocado, peanut, rice bran, grapeseed, corn, safflower, soybean, and linseed oils) at a final concentration of $100 \mathrm{mg} / \mathrm{L}$ squalene, recoveries of squalene were between 95 and 105\%.

Squalene contents in extra virgin olive oils were analyzed by the proposed HPLC method (Table 1 A1-A10). Representative chromatograms are shown in Fig. 1. These contents ranged from $3170 \mu \mathrm{g} / \mathrm{mL}$ to $6870 \mu \mathrm{g} / \mathrm{mL}$ and the average value was $4310 \mu \mathrm{g} / \mathrm{mL}$, which contents were similar to those $(1.10 \mathrm{mg} / \mathrm{g}-8.39 \mathrm{mg} / \mathrm{g})$ reported by Beltran et $a l .{ }^{20)}$. Squalene contents in extra virgin olive oils were similar to a level in virgin olive oil sample also in this work, but were higher than those of pure olive oil samples. Squalene could be detected in 8 kinds of vegetable oils (sunflower, grapeseed, avocado, linseed, corn, soybean, rice bran, and peanut oils) as well as in blended oils, but these squalene levels were significantly lower than those in extra virgin olive oils.

\subsection{Analysis of tyrosol}

Phenolic compounds in seed oils have been analyzed by HPLC with pretreatments ${ }^{18,21,24,25-28)}$. Bendini et al. ${ }^{24)}$ studied extraction methods using solid-phase extraction with three stationary phases (C8, C18, and diol) and liquidliquid extraction with $n$-hexane/methanol/water. Recovery of 15 phenolics with liquid-liquid extraction was higher than that with solid-phase extraction. However, washing with $n$-hexane after liquid-liquid extraction was conducted and long analysis times were needed, because seed oils contain many kinds of phenolics. Among the phenolics, tyrosol is known to be one of the most abundant compounds. Vegetable oil sample $(4 \mathrm{~mL})$ was mixed with $4 \mathrm{~mL}$ of acetonitrile and the mixture were vigorously shaken. After centrifuging, the upper phase (acetonitrile phase) was applied to an HPLC method. Analysis only for an analyte brought about a short analysis time and a simple pretreatment.

Tyrosol was subjected to the proposed HPLC method described in Experimental section. LOD and LOQ of tyrosol were $0.001 \mathrm{mM}(0.138 \mathrm{mg} / \mathrm{L})$ and $0.003 \mathrm{mM}(0.414$ $\mathrm{mg} / \mathrm{L})$, respectively. Linearity $\left(\mathrm{r}^{2}>0.999\right)$ was demonstrated in the concentration range of $0.003-10 \mathrm{mM}$ by standard curve (10 points)for tyrosol. The repeatability of five consecutive determinations of tyrosol was evaluated at 0.01 $\mathrm{mM}, 0.1 \mathrm{mM}$, and $1 \mathrm{mM}$. Good repeatabilities of peak areas $(\mathrm{RSD}<1.1 \%)$ and retention times $(\mathrm{RSD}<0.2 \%)$ were obtained. Interday repeatabilities of peak areas and retention time of tyrosol in three days $(n=5$, each day) were $0.3 \%$ and $0.1 \% \mathrm{RSD}$, respectively, at $0.1 \mathrm{mM}$. When a $4 \mathrm{~mL}$ of 0.1 $\mathrm{mM}$ tyrosol-acetonitrile solution was added to $4 \mathrm{~mL}$ of each oil sample ( 7 extra virgin olive oils, 2 sunflower oils, a safflower oil, and a rapeseed oil), recoveries of tyrosol were between 97 and 105\%.

Tyrosol contents in extra virgin olive oils were analyzed by the proposed HPLC method (Table 1 A1-A10). Representative chromatograms are shown in Fig. 2. These contents ranged from $4.14 \mu \mathrm{g} / \mathrm{mL}$ to $30.2 \mu \mathrm{g} / \mathrm{mL}$ and the average value was $16.0 \mu \mathrm{g} / \mathrm{mL}$, which contents were similar to those $(1.9 \mu \mathrm{g} / \mathrm{g}-64.7 \mu \mathrm{g} / \mathrm{g})$ reported previously ${ }^{19,24,25-28)}$. Range of tyrosol contents was larger than that of squalene contents in extra virgin olive oils. This result agreed well with previous reports. Variety of phenolic contents, as well as squalene, in virgin olive oils could resulted from geo- 
T. Hayakawa, M. Yanagawa, A. Yamamoto et al.

Table 1 Contents of squalene and tyrosol in vegetable oils.

\begin{tabular}{|c|c|c|c|}
\hline Vegetable oil & & Squalene $(\mu \mathrm{g} / \mathrm{mL})$ & Tyrosol $(\mu \mathrm{g} / \mathrm{mL})$ \\
\hline \multirow[t]{10}{*}{ Extra virgin olive oil } & $\mathrm{A} 1$ & $3650 \pm 35.6^{\mathrm{a}}$ & $30.2 \pm 0.165$ \\
\hline & $\mathrm{A} 2$ & $3560 \pm 5.72$ & $27.0 \pm 0.0687$ \\
\hline & $\mathrm{A} 3$ & $4640 \pm 8.09$ & $24.8 \pm 0.0848$ \\
\hline & $\mathrm{A} 4$ & $5210 \pm 34.2$ & $12.2 \pm 0.0619$ \\
\hline & A5 & $4170 \pm 5.75$ & $15.0 \pm 0.0912$ \\
\hline & A6 & $4180 \pm 5.02$ & $8.82 \pm 0.0260$ \\
\hline & A7 & $3510 \pm 33.5$ & $4.14 \pm 0.0393$ \\
\hline & $\mathrm{A} 8$ & $4140 \pm 67.7$ & $10.7 \pm 0.0890$ \\
\hline & A9 & $6870 \pm 25.2$ & $5.22 \pm 0.0288$ \\
\hline & $\mathrm{A} 10$ & $3170 \pm 10.3$ & $21.8 \pm 0.00870$ \\
\hline Virgin olive oil & A11 & $4740 \pm 12.9$ & $23.7 \pm 0.250$ \\
\hline \multirow[t]{2}{*}{ Pure olive oil } & $\mathrm{A} 12$ & $2440 \pm 16.9$ & $3.35 \pm 0.0151$ \\
\hline & $\mathrm{A} 13$ & $2170 \pm 33.9$ & $3.66 \pm 0.0306$ \\
\hline \multirow[t]{5}{*}{ Sunflower oil } & $\mathrm{B} 1$ & $31.6 \pm 0.426$ & $\mathrm{ND} 2^{\mathrm{c}}$ \\
\hline & B2 & $62.1 \pm 0.787$ & ND2 \\
\hline & B3 & $119 \pm 1.14$ & ND2 \\
\hline & B4 & $85.1 \pm 1.31$ & ND2 \\
\hline & B5 & $95.2 \pm 2.81$ & ND2 \\
\hline \multirow[t]{2}{*}{ Grapeseed oil } & B6 & $29.7 \pm 1.13$ & ND2 \\
\hline & B7 & $21.8 \pm 0.545$ & ND2 \\
\hline \multirow[t]{2}{*}{ Avocado } & B8 & $194 \pm 3.28$ & ND2 \\
\hline & B9 & $417 \pm 3.43$ & ND2 \\
\hline Linseed oil & $\mathrm{B} 10$ & $3.62 \pm 0.724$ & ND2 \\
\hline Corn oil & $\mathrm{B} 11$ & $35.3 \pm 1.07$ & ND2 \\
\hline Soybean oil & $\mathrm{B} 12$ & $36.7 \pm 0.831$ & ND2 \\
\hline Rice bran oil & $\mathrm{B} 13$ & $326 \pm 9.08$ & ND2 \\
\hline Peanut oil & B14 & $132 \pm 1.43$ & ND2 \\
\hline Safflower oil & $\mathrm{B} 15$ & $\mathrm{ND} 1^{\mathrm{b}}$ & ND2 \\
\hline \multirow[t]{2}{*}{ Rapeseed oil } & B16 & ND1 & ND2 \\
\hline & $\mathrm{B} 17$ & ND1 & ND2 \\
\hline \multirow[t]{6}{*}{ Blended oil } & $\mathrm{C} 1$ & $760 \pm 16.9$ & $2.35 \pm 0.0457$ \\
\hline & $\mathrm{C} 2$ & $286 \pm 3.63$ & $2.68 \pm 0.0274$ \\
\hline & $\mathrm{C} 3$ & $1190 \pm 11.5$ & ND2 \\
\hline & $\mathrm{C} 4$ & $212 \pm 2.55$ & $1.48 \pm 0.00218$ \\
\hline & $\mathrm{C} 5$ & $1470 \pm 11.1$ & $1.66 \pm 0.00459$ \\
\hline & $\mathrm{C} 6$ & $1600 \pm 9.19$ & $2.09 \pm 0.0273$ \\
\hline
\end{tabular}

a. Mean \pm standard deviation, $\mathrm{n}=3$.

b. Less than $0.84 \mu \mathrm{g} / \mathrm{mL}$.

c. Less than $0.138 \mu \mathrm{g} / \mathrm{mL}$. 
(A) Standard solution $[30 \mathrm{mV}$

(B) Extra virgin olive oil

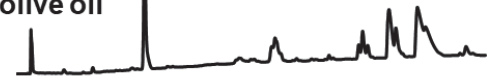

(C) Sunflower oil

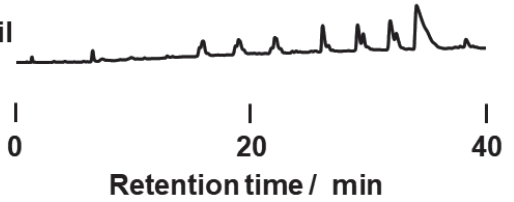

Fig. 1 Chromatograms of squalene in standard(A), extra virgin olive oil (B), and sunflower oil (C).

(A) Standard solution

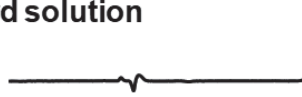

(B) Extra virgin olive oil

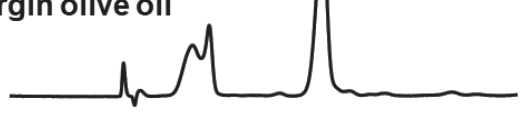

\section{(C) Sunflower oil}

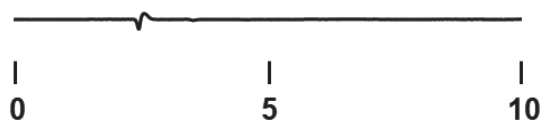

Retention time / $\mathrm{min}$

Fig. 2 Chromatograms of tyrosol in standard(A), extra virgin olive oil (B), and sunflower oil (C).

graphic origin, maturation stage, and so on ${ }^{18,25)}$. Tyrosol contents in extra virgin olive oils were similar to a level in virgin olive oil sample, but were higher than those of pure olive oil and blended oil samples. Tyrosol could be not detected in other vegetable oils.

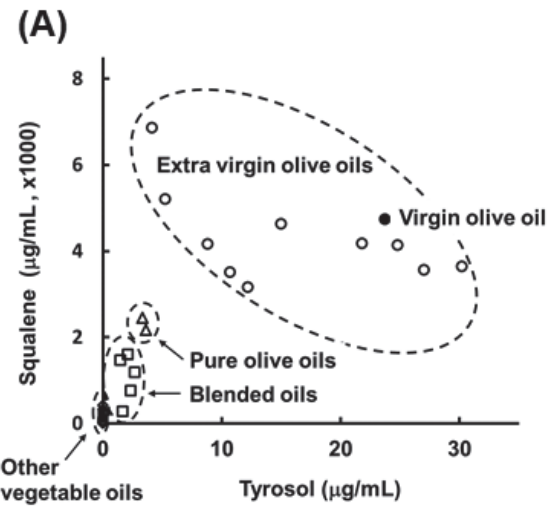

\subsection{Discrimination between extra virgin olive oils and blended oils}

Squalene contents $(3170-6870 \mu \mathrm{g} / \mathrm{mL})$ in extra virgin olive oils were higher than those of pure olive oil and blended oils $(212-2440 \mu \mathrm{g} / \mathrm{mL})$. Since the levels of squalene in virgin olive oils were reported to range from $900 \mu \mathrm{g} /$ $\mathrm{g}$ to $8700 \mu \mathrm{g} / \mathrm{g}^{29)}$, it seems to be difficult to distinguish between extra virgin olive oils and blended oils by determining only squalene content. Likewise, discrimination between extra virgin olive oils and blended oils may be difficult to determine only tyrosol content. Figure 3A shows a discrimination pattern between extra virgin olive oils and blended oils including pure olive oils, when using squalene and tyrosol contents as axes. All samples were well classified, but virgin olive oil was not discriminate from extra virgin olive oil. Since the contents of squalene were significantly higher than those of tyrosol, we tried to standardize the contents of squalene and tyrosol. Figure 3B shows scatter diagram of standard scores $(z)$ of squalene and tyrosol contents from extra virgin olive, virgin olive, pure olive, and bended oils The discrimination pattern between raw data from the four oils was found to be almost the same as that between the standard scores from the four oils. Assuming that expression of labels on oil bottles is correct, it was suggested that determination of squalene and tyrosol was useful for detecting the adulteration of commercial extra virgin olive oil, in which a large amount of adulterant seed oil was contained. In this study, we proposed a simple screening method for pure olive oils and blended oils, in which relatively large amounts of vegetable oils were added to extra virgin olive oil. Since the contents of squalene and tyrosol in virgin and extra virgin olive oils were significantly higher than those in other vegetable oils, those contents in blended oils seems to be proportional to the added ratios of virgin or extra virgin olive oils. Practically, plot area of blended oils, in which the ratio of extra virgin olive oil was $20 \%$ or $30 \%$, were overlapped with plot

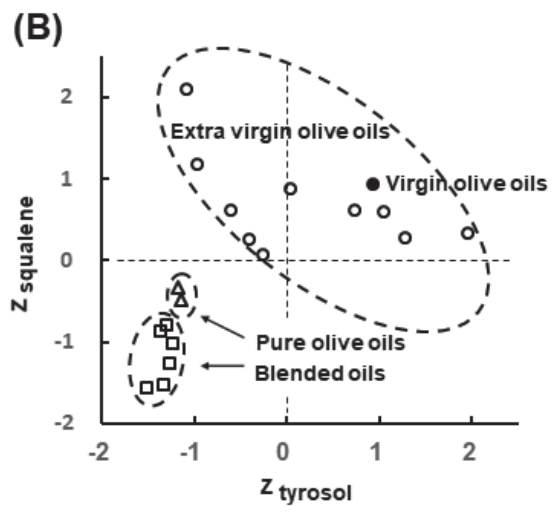

Fig. 3 Scatter diagrams of raw contents (A) and standard scores(B) of squalene and tyrosol in vegetable oils. Extra virgin olive oils (open circles), a virgin olive oil (closed circle), pure olive oils (open triangles), blended oils (open squares), and other seed oils (open rhombs). 


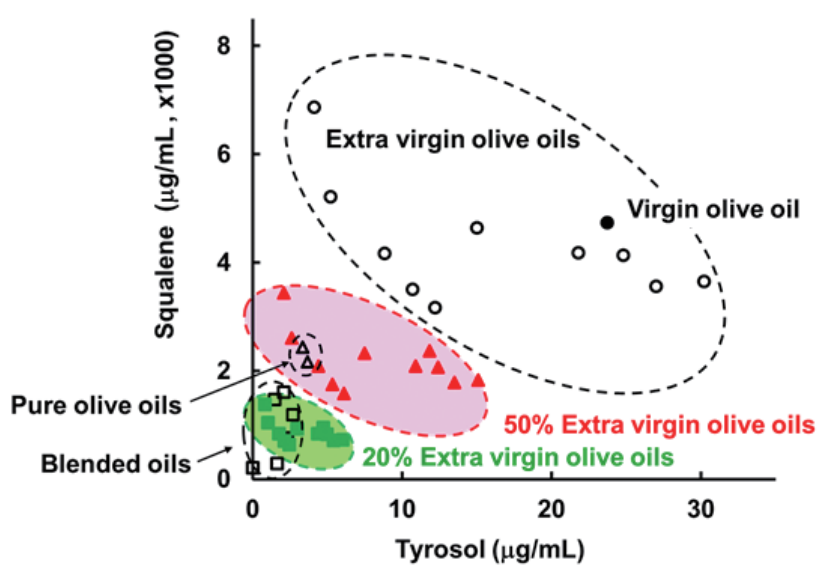

Fig. 4 Detectable percentage of extra virgin olive oil. Green and red points were 20\% and 50\%, respectively, levels of squalene and tyrosol in $100 \%$ extra virgin olive oils.

area of $20 \%$ contents of virgin and extra virgin olive oils (Fig. 4). If the above assumption is correct, plot area of $50 \%$ content of extra virgin olive oils will be differentiated from plot area of $100 \%$ contents of the oils. However, it seems that analysis of much more olive oil samples needs to determine the sensitivity of adulteration.

Many studies on stability of virgin olive oil have been reported. Manzi et $a l .{ }^{30}$ investigated contents of carotene, $\alpha$-tocopherol, and squalene from six cultivars and 15 virgin olive oils. They found that the three compounds in fruit and oil samples correlated with the olive ripeness index. They also reported that storage for 6 months at room temperature resulted in losses from 0 to $10 \%$ in carotene content, from 14 to $32 \%$ in $\alpha$-tocopherol content, and from 26 to $47 \%$ in squalene content. In contrast, Psomiadu and Tsimidou ${ }^{31)}$ determined contents of six compounds containing squalene during storage using for 24 months at room temperature in dark. Measurement of changes in the content of squalene revealed an insignificant decrease in three extra virgin olive oils with the exception of one oil. They also conducted a model system, in which changes in $\alpha$-tocopherol and squalene were investigated during autoxidation of olive oil stripped of antioxidants and pro-oxidants at $60^{\circ} \mathrm{C}$ in dark. $\alpha$-Tocopherol was gradually decreased and was not detected after $400 \mathrm{~h}$. No squalene loss was observed even in the presence of $\alpha$-tocopherol, suggesting that squalene was quite stable during autoxidation. Rastrelli et $a l .{ }^{32)}$ studied changes in the concentration of 5 compounds containing squalene in olive oil during 12 months at various storage conditions. Loss (15\%) of squalene content in dark glass bottles under diffused light was almost the same as that (19\%) of squalene content in colorless bottle. But contents of squalene in half-empty dark and colorless bottles decreased to $6 \%$ and $4 \%$, respectively. These results suggest that squalene can be easily degrade by oxygen rather than light. Hrncirik and Fritsche ${ }^{33)}$ studied relation between the endogenous antioxidant system and the quality of extra virgin olive oil under accelerated storage conditions $\left(60^{\circ} \mathrm{C}\right.$, dark). They suggested that squalene showed high stability toward autoxidation under the accelerated storage conditions.

Kalua et $a l .{ }^{34)}$ studied discrimination of storage conditions and freshness in virgin olive oil. Tyrosol level in virgin olive oil during storage for 12 months at ambient temperature decreased to $89 \%$ in the dark and $83 \%$ in the light. The two main families of complex phenolic compounds in virgin olive oil (secoiridoids) are the derivatives of hydroxytyrosol(dialdehydic and aldehydic forms of elenolic acid linked to hydroxytyrosol) and of tyrosol (dialdehydic and aldehydic forms of elenolic acid linked to hydroxytyrosol). It was reported that contents of hydroxytyrosol and tyrosol derivatives in virgin olive oil decreased during storage and that the decrease rate significantly depended on the storage temperature $^{35)}$. The decrease in secoiridoid derivatives gave rise to the simple phenols (hydroxytyrosol and tyrosol) and to the formation of oxidized products ${ }^{36)}$.

As mentioned above, contents of squalene and tyrosol in extra virgin olive oil, which were analyzed for discrimination of extra virgin olive oil adulteration, substantially can be affected by storage conditions. However, levels of the two analytes are seemed to be significantly affected by olive varieties compared to storage conditions.

\section{Conclusion}

Squalene and tyrosol in commercial seed oils were determined by HPLC with simple pretreatments. Contents of squalene and tyrosol in extra virgin olive oils were higher than those in pure olive oils, blended oils, and other vegetable oils. When squalene contents were plotted against tyrosol contents, extra virgin olive oils were clearly discriminated from pure olive oils, blended oils, and other vegetable oils, but not virgin olive oil. Therefore, it is suggested that determination of squalene and tyrosol was useful for the screening method of discrimination between extra virgin olive oil and blended oil using HPLC with simple pretreatments.

\section{References}

1) Codex Alimentarius. Joint FAO/WHO International Food Standards. Standard for olive oils and olive pomace oils (Codex Stan 33-1981, Rev. 2015).

2) Official Journal of the European Union. Commission implementing regulation (EU) No 1348/2013 of 16 December 2013 amending regulation(EEC) No 2568/91 on the characteristics of olive-residue oil and on the 


\section{A Simple Screening Method for EVOO Adulteration}

relevant methods of analysis.

3) Federal Register. Department of agriculture, Agricultural marketing service. United States Standards for Grades of Olive Oil and Olive-Pomace Oil. Vol. 75, No 81/Wednesday, April 28, 2010/Notices.

4) Karunathilaka, S.R.; Kia, A.-R.F.; Srigley, C.; Chung, J.K.; Mossoba, M.M. Nontargeted, rapid screening of extra virgin olive oil products for authenticity using near-infrared spectroscopy in combination with conformity index and multivariate statistical analyses. $J$. Food Sci. 81, C2390-C2397 (2016).

5) Ghanbari, R.; Anwar, F.; Alkharfy, K.M.; Gilani, A.-H.; Saari, N. Valuable nutrients and functional bioactives in different parts of olive (Olea europaea L.)-A review. Int. J. Mol. Sci. 13, 3291-3340(2012).

6) Purcaro, G.; Barp, L.; Conte, L. Comparison of different injection modes in edible oil minor components analysis. J. Sep. Sci. 38, 2278-2285 (2015).

7) Servili, M.; Montedoro, G.F. Contribution of phenolic compounds to virgin olive oil quality. Eur. J. Lipid Sci. Technol. 104, 602-613(2002).

8) Hoed, V.V. Phenolic compounds in seed oils. Lipid Technol. 22, 247-249(2010).

9) Bosque-Sendra, J.B.; Cuadros-Rodriguez, L.; RuizSamblas, C.; de la Mata, A.P. Combining chromatography and chemometrics for the characterization and authentication of fats and oils from triacylglycerol compositional data-A review. Anal. Chim. Acta 724, 1-11 (2012).

10) Azizian, H.; Mossoba, M.M.; Fardin-Kia, A.R.; Delmonte, P.; Karunathilaka, S.R.; Kramer, J.G. Novel, rapid identification, and quantification of adulterants in extra virgin olive oil using near-infrared spectroscopy. Lipids 50, 705-718(2015).

11) Gurdeniz, G.; Ozen, B. Detection of adulteration of extra-virgin olive oil by chemometric analysis of mid-infrared spectral data. Food Chem. 116, 519-525 (2009).

12) Maggio, R.M.; Cerretani, L.; Chiavaro, E.; Kaufman, T.S.; Bendini, A. A novel chemometric strategy for the estimation of extra virgin olive oil adulteration with edible oils. Food Control. 21, 890-895 (2010).

13) Zou, M.-Q.; Zhang, X.-F.; Qi, X.-H.; Ma, H.-L.; Dong, Y.; Liu, C.-W.; Guo, X.; Wang, H. Rapid authentication of olive oil adulteration by raman spectrometry. J. Agric. Food Chem. 57, 6001-6006 (2009).

14) Jabeur, H.; Zribi, A.; Makni, J.; Rebai, A.; Abdelhedi, R.; Bouaziz, M. Detection of Chemlali extra-virgin olive oil adulteration mixed with soybean oil, corn oil, and sunflower oil by using GC and HPLC. J. Agric. Food Chem. 62, 4893-4904(2014).

15) Yang, Y.; Ferro, M.D.; Cavaco, I.; Liang, Y. Detection and identification of extra virgin olive oil adulteration by GC-MS combined with chemometrics. J. Agric. Food Chem. 61, 3693-3702(2013).
16) Fasciotti, M.; Netto, A.D.P. Optimization and application of methods of triacylglycerol evaluation for characterization of olive oil adulteration by soybean oil with HPLC-APCI-MS-MS. Talanta 81, 1116-1125 (2010).

17) Parcerisa, J.; Casals, I.; Boatella, J.; Codony, R.; Rafecas, M. Analysis of olive and hazelnut oil mixtures by high-performance liquid chromatography-atmospheric pressure chemical ionization mass spectrometry of triacylglycerols and gas-liquid chromatography of nonsaponifiable compounds (tocopherols and sterols). J. Chromatogr. A 881, 149-158(2000).

18) Tasioula-Margari, M.; Okogeri, O. Isolation and characterization of virgin olive oil phenolic compounds by HPLC/UV and GC-MS. J. Food Sci. 66, 530-534 (2001).

19) Owen, R.W.; Mier, W.; Giacosa, A.; Hull, W.E.; Spiegelhalder, B.; Bartsch, H. Phenolic compounds and squalene in olive oils: the concentration and antioxidant potential of total phenols, simple phenols, secoiridoids, lignans and squalene. Food Chem. Toxicol. 38, 647659 (2000).

20) Beltran, G.; Bucheli, M.E.; Aguilera, M.P.; Belaj, A.; Jimenez, A. Squalene in virgin olive oil: Screening of variability in olive cultivars. Eur. J. Lipid Sci. Technol. 118, 1250-1253 (2016).

21) Brenes, M.; Garcia, A.; Garcia, P.; Rios, J.J.; Garrido, A. Phenolic compounds in Spanish olive oils. J. Agric. Food Chem. 47, 3535-3540 (1999).

22) Grigoriadou, D.; Androulaki, A.; Psomiadou, E.; Tsimidou, M.Z. Solid phase extraction in the analysis of squalene and tocopherols in olive oil. Food Chem. 105, 675-680 (2007).

23) Alberdi-Cedeno, J.; Ibargoitia, M.L.; Cristillo, G.; Sopelana, P.; Guillen, M.D. A new methodology capable of characterizing most volatile and less volatile minor edible oils components in a single chromatographic run without solvents or reagents. Detection of new components. Food Chem. 221, 1135-1144(2017).

24) Bendini, A.; Bonoli, M.; Cerretani, L.; Biguzzi, B.; Lercker, G.; Toschi, T.G. Liquid-liquid and solid-phase extractions of phenols from virgin olive oil and their separation by chromatographic and electrophoretic methods. J. Chromatogr. A 985, 425-433 (2003).

25) Reboredo-Rodriguez, P.; Rey-Salgueiro, L.; Regueiro, J.; Gonzalez-Barreiro, C.; Cancho-Grande, B.; SimalGandara, J. Ultrasound-assisted emulsification-microextraction for the determination of phenolic compounds in olive oils. Food Chem. 150, 128-136 (2014).

26) Jimenez, M.S.; Velarte, R.; Castillo, J.R. Direct determination of phenolic compounds and phospholipids in virgin olive oil by micellar liquid chromatography. Food Chem. 100, 8-14(2007).

27) Hrncirik, K.; Fritsche, S. Comparability and reliability 
of different techniques for the determination of phenolic compounds in virgin olive oil. Eur. J. Lipid Sci. Technol. 106, 540-549 (2004).

28) Ramos-Escudero, F.; Morales, M.T.; Asuero, A.G. Characterization of bioactive compounds from monovarietal virgin olive oils: Relationship between phenolic compounds-antioxidant capacities. Int. J. Food Prop. 18, 348-358 (2015).

29) De Leonardis, A.; Maccionale, V.; De Felice, M. Rapid determination of squalene in various olive oils using gas-liquid chromatography. Ital. J. Food Sci. 10, 75-80 (1998).

30) Manzi, P.; Panfili, G.; Esti, M.; Pizzoferrato, L. Natural antioxidants in the unsaponifiable fraction of virgin olive oils from different cultivars. J. Sci. Food Agric. 77, 115-120 (1998).

31) Psomiadou, E.; Tsimidou, M. Stability of virgin olive oil. 1. Autoxidation studies. J. Agric. Food Chem. 50, 716-721 (2002).

32) Rastrelli, L.; Passi, S.; Ippolito, F.; Vacca, G.; De Sim- one, F. Rate of degradation of $\alpha$-tocopherole, squalene, phenolics, and polyunsaturated fatty acids in olive oil during different storage conditions. J. Agric. Food Chem. 50, 5566-5570 (2002).

33) Hrncirik, K.; Fritsche, S. Relation between the endogenous antioxidant system and the quality of extra virgin olive oil under accelerated storage conditions. $J$. Agric. Food Chem. 53, 2103-2110(2005).

34） Kalua, C.M.; Bedgood JR., D.R.; Bishop, A.G.; Prenzler, P.D. Discrimination of storage conditions and freshness in virgin olive oil. J. Agric. Food Chem. 54, 71447151 (2006).

35) Krichene, D.; Salvador, M.D.; Fregapane, G. Stability of virgin olive oil phenolic compounds during long-term storage (18 months) at temperatures of 5-50 $0^{\circ}$. J. Agric. Food Chem. 63, 6779-6786 (2015).

36) Kotsiou, K.; Tasioula-Margari, M. Monitoring the phenolic compounds of Greek extra-virgin olive oils during storage. Food Chem. 200, 255-262 (2016). 